\title{
Games as Systems for Rehabilitation: a Design Strategy for Game-based Exercise Rehabilitation for Parkinson's disease
}

\author{
A. Tece Bayrak \\ Media Design School \\ tece.bayrak@mediadesign \\ school.com
}

\author{
Burkhard C. Wünsche \\ University of Auckland \\ burkhard@.cs.auckland.ac. \\ $\underline{\mathrm{nz}}$
}

\author{
Stacey A. Reading \\ University of Auckland \\ s.reading@auckland.ac.nz
}

\author{
Christof Lutteroth \\ University of Bath \\ c.lutteroth@bath.ac.uk
}

\begin{abstract}
Games are of interest for health interventions including but not limited to physical activity and rehabilitation, behavior change, motor-cognitive training, and mood elevation. Despite increased interest in using games to produce positive health outcomes, the development or selection process of games, or their suitability for a target demographic in a context of health and rehabilitation, remains ad-hoc. As a result, game-based interventions lacking application specificity produce variable outcomes that obscure the true treatment effect of game-based therapies. To address this issue, we present a design strategy for game-based rehabilitation that uses a player-centric approach to develop/select games for specific contexts such as for improving functional deficits in patients with Parkinson's disease. This strategy establishes a relationship between the exercise rehabilitation regimen and gameplay by incorporating the rehabilitation requirements, patient condition, and player affordances, into the game world. In addition, we present guiding questions to support the application of the design strategy for improving the effectiveness of game-based rehabilitations.
\end{abstract}

\section{Introduction}

Parkinson's disease (PD) is a progressive neurodegenerative disorder presenting with motor and non-motor symptoms that decrease functional ability, quality of life, and reduce independence. There is no cure, but symptoms and diminishing physical function can be mitigated using exercise-based therapies appropriate for different stages of the disease [1].

Functional self-efficacy is a key element of chronic disease management [49] and this is often facilitated by using exercise illustrations, charts, and videos. However, effectiveness of these low clinician contact approaches have not yet been well established and they limit the amount of supervision provided to moderate performance of the intervention [51]. Game technology as a rehabilitation, training or treatment tool has become increasingly popular in the literature with examples for PD [2], motor-cognitive training for elders [4], active physical therapy for all ages [5], children's health [6], and psychotherapy [7]. Playful and entertaining qualities of games are regarded beneficial for social and psychological health in older adults $[3,52]$.

Patients' ability to perform in a commercial game that presents challenges in the areas affected by the symptoms of the disease is limited [2]. This means games for PD rehabilitation need to be tailored to accommodate patient limitations while also delivering the designed rehabilitation strategy aimed at improving functional deficits. A review of the rehabilitation literature shows that most practitioners and researchers use commercial "off the shelf" games [53] and study how this game play affects patient function. There is a paucity in the literature outlining game design principles for rehabilitation applications.

We present a strategy for selecting or developing a game-based intervention that appropriately engages the patient-player while also providing appropriate stimuli to meet specific rehabilitation targets and goals required for treatment. Our target demographic are early stage PD patients (Hoehn and Yahr scale stage 1-2). Our starting research question is: (RQ) What would be a suitable game design strategy to develop games for rehabilitation without sacrificing the motivational aspects of a game? Considering rehabilitation goals and rehabilitation tasks, a sub-question is: (RQ1) Which methods can be used to integrate rehabilitation/training tasks into a game? Since early stage PD symptoms can vary significantly and affect both cognition and motor function, another sub-question is: (RQ2) How can we approach game design, in order to design more compassionate and engaging game experiences for a special target demographic? 


\section{Literature Review}

The literature on game based rehabilitation, particularly for PD, includes studies from several disciplines such as rehabilitation medicine, exercise science, neuroscience, and computer science. Despite inconsistent clinical evidence, studies show promising results for the contribution of physical exercise $[18,19]$ and cognitive training-with games $[10,11,13]$ or computerized cognitive training [10, 12]. Physicalactivity-based commercial games (with peripherals such as Kinect or WiiFit) have been used for motor-cognitive training $[2,9]$, but they do not offer customized game play to meet patients' needs. Also, it is often unclear why certain games are selected for an intervention [2].

Custom games hold promise for providing a tailored experience $[9,14,15,16]$ even though several of these present concern for disengagement once the novelty of the game play experience fades away. A common issue is a lack of rationale on how an approach from one study can be reapplied to meet the needs of another rehabilitation or treatment for another target demographic. Even though design principles have emerged in some studies $[14,15,16,17]$, their application remains unclear because the transfer between rehabilitation tasks and games appears arbitrary. While some game principles (such as timely feedback, clear goals and instructions, challenge vs. skill, empowerment with choice, meaningful actions, social context) are commonly applicable to game design regardless of the rehabilitation-focused activities, there is very little clarity on how they come together to create a game. Moreover, there is no exploration on the contextual narrative elements of games and their place in designing game-based rehabilitation [2]. Few studies appreciate the necessity of interdisciplinary collaboration and incorporation of clinical techniques, neuroscience and multimedia technology in order to develop an effective intervention [17, 22].

Although PD has many neurologic symptoms, in stage 1 and $2 \mathrm{PD}$, there is evidence supporting improvement in aerobic capacity as a means to mitigate some of the cognitive decline experienced by these patients [18]. In exercise rehabilitation for PD, intensity of an exercise, its duration, modality and its regimen over time are decided based on the rehabilitation goals as well as the status of the patient $[18,19,20]$. Variety in exercise regimen and gradual increase in intensity related variables (difficulty, duration, etc.) may allow for a steadier development of aerobic capacity [23]. Different requirements with regard to exercise intensity have important implications for game design, since they might result in different game play, and safety requirements.
Lohse et al. [17] suggested that with "good" game design, games could increase the dosage of exercise rehabilitation by alleviating non-adherence due to their motivating nature. Based on physiological systems of motivation and engagement, and rehabilitation science, they proposed six key considerations for game design: reward, difficulty/challenge, feedback, interactivity, clear goals and mechanics, and socialization. In addition, their review presented a collection of gameplay conditions that induce dopamine release hypothesizing that a "dopamine-general reward system underlies gameplay" [17]. These conditions are visceral pleasures, decision making that resolves to a successful or close to successful result, anticipation of rewards, and exploratory behavior. Even though the breadth of the review is limited to confirm their hypotheses, it clearly opens the path for further research on the relation of gameplay and the neuroscience of reward and motivation. This strengthens the suggestion that games as systems of rehabilitation can be considered as digital therapeutics [6] that integrate game design with neuroscience, psychology and theories of rehabilitation.

\section{Background}

Building on existing game design theory [24, 25, 26, 27], we use a "research through design" approach [50]. The following subsections present a synthesis of the core material in the intersection of game design and rehabilitation.

\subsection{Game design in scope of rehabilitation}

By nature, games encourage voluntary participation to overcome virtual challenges in order to reach a virtual goal. The challenges and goals are driven by objectives shaped by rules that define the boundaries of the tasks. In fact, they are complex systems that enclose complex relationships and interaction paradigms prone to emergence [26, 29]. When considered as systems for rehabilitation, games need to enclose four key elements; (1) the purpose of a rehabilitation, (2) training steps and nurturing involved with these steps, (3) causality in the rehabilitation strategy, and (4) evaluation for the current status of the participant during rehabilitation. Perhaps, a fifth element in addition to these could be (5) dynamic adaptation to the current status of a participant (e.g., improved function or training responses or exacerbation of symptoms during periods of disease progression). Therefore, a game becomes a system for rehabilitation with the transfer of these elements into game elements.

Game design principles aim to help a designer curate an engaging experience for players [28]. Various approaches for designing a game have been published and perhaps used in combination, yet one concrete set 
of apply-to-all game design methods does not really exist [30]. In player-centric design, the main purpose is making the designer take the perspective of the player. This is an important consideration when designing games for patients with chronic illness because functional limitations may impact on what type of tasks the individual can perform or the patient player may maybe motivated differently (e.g., to achieve rehabilitation benefit vs. experience gameplay enjoyment). The importance of understanding a player's perspective, desires, drives, and barriers cannot be overstated when designing games for a rehabilitation application. This means, motivational values of the experience have to be aligned with the player while goals of the experience are aligned with the rehabilitation. Therefore, goals need special attention in context of rehabilitation and games.

Merging rehabilitation and play brings additional challenges to the curation of a motivating play activity in a suitable emotional context. Moreover, motor and cognitive difficulties such as reduced range of motion or difficulty in decision making as seen in PD, will affect players' skill and ability to perform in the game. This requires special consideration and fine-tuning of the games elements. Hence, in order to explore game design in the scope of rehabilitation; we need to look at goals, experience of play, and skill and ability in this context.

\subsection{Goals in context of rehabilitation and games}

Goals and objectives are essential game design elements that drive an experience towards a perceivable conclusion. They cascade from inner micro-loops of a game to the outer game-loop, supported by contextual elements of the game. For example, in Super Mario Bros. the overarching goal of the game is saving the princess (contextual goal). However, the goal in each level is to reach the castle, hence beating the level. In order to beat the level, a player needs to avoid the enemies and traverse the platforms. When an ability is given to the player (i.e. reaching to higher areas with your jump), it is restricted by a modifier (e.g., Mario increasing in size). Acquiring this ability (eating a red mushroom) becomes an interim objective due to its usefulness. Therefore, goal or objective centered behavior becomes intertwined in game design and player strategy rather than being directly manifested by the game.

On the other hand, design goals of a game (authorial intent) can be different from the goals in the game. Using football as an example, one can argue that the design goal of the game is practicing collaboration in teams. Yet, a player's goal is to score goals. In the context of rehabilitation games, a design goal of the game is to motivate the player into continuing play thereby continuing to engage in rehabilitation to improve the overall rehabilitation outcomes. Hence, the game experience must match the interest of the playerpatient. Thus, rehabilitation goals should be broken down into measurable items and dispersed across the game elements during game design process.

\subsection{On experience of play}

Understanding play and its driving forces carries utmost importance for game design. Motivation to play, ability to play, and preferences of play are discussed here to layout the basics towards creating a motivating game experience.

3.3.1. Motivation. According to Self Determination Theory (SDT), human motivation is based on three basic psychological needs: competence, autonomy, and relatedness [32]. Competence is the universal will to get better at performing something; autonomy is the universal urge to have agency on one's own choices; relatedness is the universal pursuit to form connections and find where one belongs. These translate into measurable domains with the Player Experience Needs Satisfaction (PENS) model [33]. PENS suggests that when a play experience fulfills these three needs within the context of the game world, players experience higher satisfaction. The authors state "[the] approach looks beyond the surface level emotional expressions of "fun" and focuses on the basic psychological needs that games can satisfy." [33].

Even though these motivational aspects encourage continuation of play, there is a "taste factor" involved in a player's choice to start playing [58]. Correlations between motivation and taste may exist, but are not supported by any research. In the design process, a satisfaction map [48] can be helpful to find intended core values of a game.

3.3.2. Playability and optimal play experience. It is often argued that a balance between skill and challenge creates an optimal experience for a person in any kind of performance; this is considered as being in flow [40]. With flow theory, Csikszentmihalyi explains that there are seven core components of flow categorized under conditions and characteristics [40]. Conditions (clear tasks, feedback, concentration, attainable goal) act as the prerequisites of flow while characteristics (control, diminished awareness of self, altered sense of time) refer to the experience of the individual in the state of flow. Moreover, maintaining this balance is one of the most critical prerequisites for flow and it is important for both motivation and learning [40]. Therefore, in order to maintain engagement and promote flow, challenges should match player growth in skill for 
attainability while tasks and goals are clear, feedback is timely and readable, and distractions are minimized.

3.3.3. Play preferences. Player types-killers, achievers, socializers, and explorers were born from research into players' interest in a Multi User Dungeon (MUD) [42]. Over time, various interpretations of player types were developed [46] including diverse angles based on actions that generate emotions of fun, such as exploration fulfilling curiosity or character creation fulfilling the need of self-expression [29]. Lazzaro [31] suggests that emotional spectrum of games is the reason why people play, and captivating game experiences provide at least three of the four types of fun (fiero, curiosity, relaxation/excitement, amusement) as players alternate between these emotions.

Similarly, Engines of Play is a method that can identify correlations between game features and player personality types to enable "more accurate empathy" for players [58]. It relies on the Big Five psychological model (known as OCEAN) that is mapped to five discrete domains: openness, conscientiousness, extraversion, agreeableness, and neuroticism. However, after a few applications, the fifth domain is reported to be less meaningful in play-context [34, 47]. Therefore, the first four (openness, conscientiousness, extraversion, agreeableness) translate to four domains of play (in order) as: novelty, challenge, stimulation, harmony. VandenBerghe further developed this into taste maps to identify domains of play in relation to personality traits and game features [48].

Table 1. Domains of play and play preferences

\begin{tabular}{|l|l|l|}
\hline $\begin{array}{l}\text { Domains } \\
\text { of play }\end{array}$ & Influential scales & $\begin{array}{l}\text { Stereotype } \\
\text { example }\end{array}$ \\
\hline Novelty & $\begin{array}{l}\text { Fantasy - Realism } \\
\text { Builds - Explores }\end{array}$ & $\begin{array}{l}\text { F\&B: Inventor } \\
\text { F\&E: Adventurer }\end{array}$ \\
\hline Stimulation & $\begin{array}{l}\text { Calm - Trill } \\
\text { Solo - Multiplayer }\end{array}$ & $\begin{array}{l}\text { C\&S: Hermit } \\
\text { C\&M: Shepherd }\end{array}$ \\
\hline Challenge & $\begin{array}{l}\text { Skilled - Less Skilled } \\
\text { Work - Casual }\end{array}$ & $\begin{array}{l}\text { S\&: Master } \\
\text { LS\&W:Perseverer }\end{array}$ \\
\hline Harmony & $\begin{array}{l}\text { Collaborate } \\
\text { Compete }\end{array}$ & $\begin{array}{l}\text { Col\&A: Soldier } \\
\text { Ctx\&Com: } \\
\end{array}$ \\
& Context - Action & Knight \\
\hline
\end{tabular}

Table 1 shows domains of play and influential scales to inform development of gameplay features. Each domain of play may enclose various scales of influences for which edge cases can be considered as stereotypes.

\subsection{Skill and ability}

Understanding skill and ability is a delicate issue when it comes to special demographics whose abilities are limited by pathological processes related to illnesses such as PD. Skill, as per the definition we use from the dictionary", is "dexterity or coordination especially in the execution of learned physical tasks"; ability ${ }^{2}$ is "the quality or state of being able". Thus, players suffering from motor impairments may have the skill (originally) to perform repetitive precise tasks but are now incapable or have diminished ability to execute the skill due to progression of disease pathology. The period between being able to execute the skill to being unable to execute the skill is progressive over the course of disease progression [22]. Cognitive skills, motor skills, emotional and physical stamina decline over time as disease progresses. A similar progressive loss of function can be seen during normal aging [8]. More so than solo play, balancing becomes problematic in competitive set-ups due to variations in fitness, dexterity or endurance of participants [45].

Games require motor-cognitive interaction. Physical interaction with the game is accomplished through input mechanisms such as pressing a button, shaking a controller, moving the thumb-stick. In order to organize this interaction, players use their cognitive skills to direct their attention, prioritize and plan their moves, switch between activities, remember necessary information, and avoid anything that goes against their goals while transferring desired actions to achieve game tasks into motor outputs that manipulate the input mechanisms. Therefore, in this framework, we see players' skills and abilities as resources they have and spend. The scale of each resource for each player depends on individual's own reserves that can be limited by their disease.

\subsection{Misconceptions about games for health}

A fallacy in using exercise gaming as a rehabilitation intervention is that the exercise or physical activity will be immediately engaging for the player patient. Since games are mostly seen as entertainment devices, engagement is somewhat taken for granted. As a result, research papers repeat the same limitation about the motivational value of novelty and that when novelty fades away, the contribution of the game in an exercise rehabilitation context is unclear longitudinally.

Age-related changes to skill and ability of a player unsurprisingly affect their motivation to play, therefore their preferences [8]. However, this may not mean that there are certain play styles reserved for specific age groups or diseases. Players shying away from some play styles because their ability to play is being limited by progression of their disease symptoms does not mean that they are uninterested in game play. An alternate

\footnotetext{
${ }^{2}$ https://www.merriam-webster.com/dictionary/ability
}

\footnotetext{
${ }^{1}$ https://www.merriam-webster.com/dictionary/skill
} 
view maybe that consideration needs to be given to designing better experiences that accommodates functional decline. In addition, the notion about elders' literacy on game technology and games [8] is becoming obsolete as native-gamer generation is getting older, if not based on demographic reports for social games.

\section{Design Strategy}

This section presents our design strategy for gamebased exercise rehabilitation for special demographics.

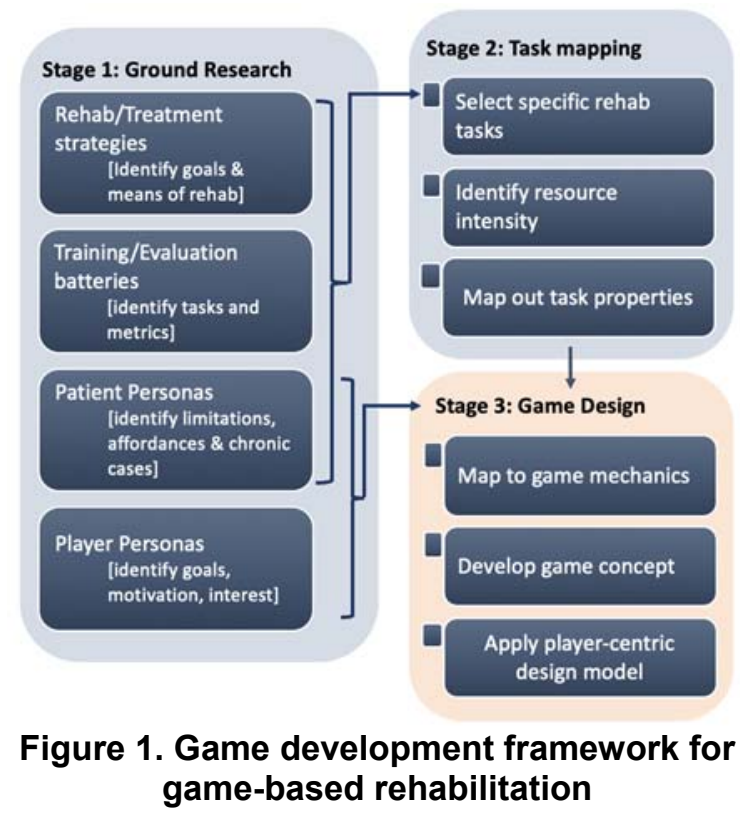

The design strategy comprises three stages; ground research, task mapping and game design as seen in Figure 1. Each stage includes details on the steps and methods suggested for that stage. Initial design requires extensive research on the problem space so that rehabilitation and training goals and related rehabilitation tasks can be identified. Stage 2 analyses these rehabilitation tasks and maps out their properties in order to inform game features. The transition from Stage 2 to Stage 3 uses an onion metaphor (Figure 2) to facilitate the jump from mapped rehabilitation tasks to game design, and Stage 3 employs a player-centric game design model to draw attention to the player (Figure 3). The following sub-sections detail each stage, and explain the methods involved in eliciting necessary information to fulfill the activities of the design strategy.

\subsection{Stage 1: Ground research}

The main methods used in ground research are shown in Table 2. The process should begin with a thorough review of relevant research to outline the target disease pathology, functional impact and current rehabilitation strategies and targets. Specific goals for exercise rehabilitation can be identified and guide game design. In designing our PD rehabilitation game, the identified goal was to use aerobic exercise to improve executive function and quality of life. A literature review produced evidence that aerobic exercise improves executive function for PD patients [18, 19]. In parallel, there was convincing evidence supporting a benefit of cognitive treatment in executive function improvement [10, 12, 13, 38]. Therefore, a goal of the game design was to join the benefit of aerobic exercise and cognitive training within the game play.

Table 2. Methods for ground research

\begin{tabular}{|c|c|}
\hline Steps & Methods \\
\hline $\begin{array}{l}\text { Rehabilitation/ } \\
\text { Treatment } \\
\text { strategies }\end{array}$ & \begin{tabular}{lc}
\multicolumn{2}{l}{ Synthesis from: } \\
- & Literature reviews \\
- & Expert interviews
\end{tabular} \\
\hline $\begin{array}{l}\text { Training/ } \\
\text { Evaluation } \\
\text { batteries }\end{array}$ & \begin{tabular}{lc}
\multicolumn{2}{l}{ Synthesis from: } \\
$-\quad$ & Literature review \\
- & Expert interviews
\end{tabular} \\
\hline Patient Personas & $\begin{array}{ll}\text { Persona forming from: } \\
\text { - } & \text { Literature Review } \\
\text { - } & \text { Expert interviews } \\
\text { - } & \text { Care-giver interviews } \\
\text { - } & \text { Patient surveys, interviews, } \\
\text { observations }\end{array}$ \\
\hline Player Personas & $\begin{array}{l}\text { Persona forming: } \\
\text { - } \quad \text { Taste mapping (Engines of } \\
\text { Play-the Big Five) } \\
\text { - } \quad \text { Satisfaction map (SDT) } \\
\text { - } \quad \text { PENS }\end{array}$ \\
\hline
\end{tabular}

Training/Evaluation batteries are training and evaluation tasks used in motor-cognitive or physical rehabilitation. They provide the means of training and tracking progress, and are useful to develop difficulty tiers for the tasks in later stages (Stage 2). For example, flexible thinking is one of three main executive function skills, and the Trail Making Test (TMT) is used to train and evaluate flexible thinking.

Patient personas are used to characterize the target demographic [35]. Core information necessary to develop a patient persona is chronic cases, disease related symptoms, and limitations of the patients in emotional, physical, cognitive and motor domains as well as reservations. These limitations guide game development by identifying elements that should be excluded because of certain mechanics, difficulty adjustment, or support strategy.

Player Personas are useful for contextual layer and aesthetics. They also feed into the player perception segment of player-centric design model. We chose the Taste Mapping method due to its simplicity and 
readiness to use with players. Questions that should be asked when using this approach are: (1) "Why does a person participate in the experience?", "Why do they play?"; and (2) "What specific activity in games do they enjoy?". The answer to the first question helps in building the secondary mechanics.

\subsection{Stage 2: Task mapping}

The task mapping stage identifies and maps out properties of the selected rehabilitation tasks in order to inform game design with action points, interim goals and pacing for game mechanics once the game design stage starts. Cognitive task analysis methods are used to study a task in relation to its purpose and underlying cognitive aspects [41, 43, 44]. In the context of our study, we found these properties useful (including but not limited to): the purpose of a task, success factors, measurement strategy such as time, measure, metric, etc., and resource intensity. The resource intensity property of a task is used to adjust the complexity level during mapping of training tasks to game mechanics. A detailed task-mapping table is available as supplementary material from author's project page (https://www.researchgate.net/project/Games-ExerciseRehabilitation).

The rehabilitation tasks identified in the previous stage are analyzed for their common use, purpose and evaluation values. For example, we chose cognitive training strategies and an exercise regimen. A literature review for cognitive evaluation and training methods in non-motor aspects of the disease yielded the Tower of London Task (ToL) as one of the commonly used cognitive training and evaluation tasks [10, 12, 38, 39]. For this task, the user needs to match a given state of disks by moving them over pegs. It requires mental planning and working memory. Task difficulty relies on the number of moves required.

\subsection{Stage 3: Game design}

The supporting method for this stage is the onion metaphor as seen in Figure 2. Once task mapping is completed, primary and secondary mechanics (if necessary a third mechanic) are identified. Mechanics are actions or verbs that are performed repeatedly by the player. Mapping to the game mechanics includes these verbs that represent the core actions of the training task and the requirements of these tasks, objectives, restrictions and metrics that are developed during task mapping in the previous stage. It is necessary to note that secondary mechanic needs to work together with primary mechanic while both mechanics are dependent on the controller scheme and the interaction method. Questions to consider here are (1) "What does moment- to-moment action look like?", (2) "What is the learning curve of the mechanic?", and (3) "How intuitive is it to perform, achieve the objectives, and reach mastery?".

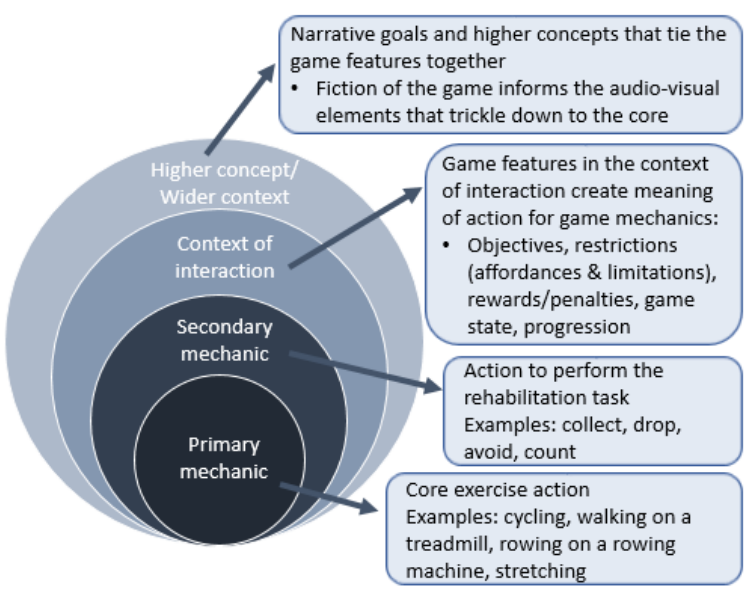

Figure 2. Onion metaphor for task transfer

For example, primary mechanic for our game is cycling, and we do not use a game controller. Players navigate in the world by pedaling a stationary cycle ergometer and all additional interactions are encapsulated into movement created by pedaling the ergometer. For the ToL task, the secondary mechanic can be collecting/delivering. In the original rehabilitation task, the user is required to move the disks from their current position to a desired position one at a time. In order to create context, the disks that are varied by color/size and the activity of organizing them could be imagined by the player as gardening actions such as ploughing, watering and planting. Each of these tasks can be designed as location/object based actions and can be performed in the same way (with the same interaction method-gaze or collision). Hence, the disks are a plough tool, a watering can or a pack of seeds whilst in alignment with the ordered fashion of ToL task. The context of interaction becomes a garden, and the players' actions are gardening actions. Thus, game features can be imagined in this context, and the formal elements of the game are planned accordingly. In this example, the player cycles in a gardening shuttle that can plough, water and plant as it interacts with a field that is ready to be ploughed, planted or watered.

\section{Applying player-centric game design model}

The last step of Stage 3 is incorporating the findings from previous stages. The model seen in Figure 3 aims to help the researchers understand the relation between the layers of a game world, player's interaction with the game world, player's perception of the system and player's resources in this system. 


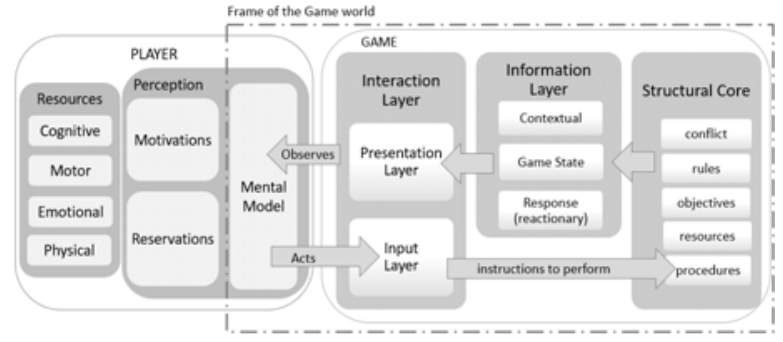

Figure 3. Player-centric game design model (layers of experience) -extended from [21]

\subsection{Player resources}

Resources refer to an account of abilities that belong to the player, and exerted by them. Their regeneration (if even possible) or their amount is player dependent although may be improved over time (as a result of successful rehabilitation if possible). This is similar to someone increasing their ability to run longer or faster as a result of undertaking exercise training. An in-game activity demands a scale of player resources (abilities) in order for them to perform.

The player resources referred in our example are cognitive resources (such as working memory, attention, reasoning, flexibility), motor resources (such as timed-response, quick-response, precision, repetition, reach), emotional resources (such as resilience, selfesteem, self-efficacy, commitment), and physical resources (such as motor coordination, dexterity, endurance, stamina, agility). It can be argued that good game design keeps players motivated by converting each failure into a success until reaching the goal. In order to obtain a successful design, designers need to study how disease pathology and symptoms affect player resources during the game.

\subsection{Player perception}

There are three important elements to player perception: their mental model, motivations and reservations. The player has a mental model through which they observe the system. This model is clouded by their interpretation of the system [36] and by their motivation and reservations. By matching the perceived affordances with the actual use [37], the system needs to suggest itself as accessible so that players can immediately know what to do and how to do it. This is established with contextual cues, guidance and readability. The literature identifies barriers to physical activity such as fear of falling/ injury/failure, poor selfimage, low self-esteem or confidence and that the reasons for discontinuation rehabilitation are a lack of motivation, depression, and accessibility [4, 8, 17, 22]. We see these as reservations of the player to start or carry on using a system. They work against motivations. Therefore, it is necessary to find ways to overcome them. For example, one of the barriers related to confidence is unfamiliarity with the technology. An interaction layer should promote familiarity to prevent this reservation from becoming a barrier to participation or continuation in game play.

\subsection{Interaction layer}

There are two ends of an interaction; the user-end and the system-end. From a user's perspective, the inner workings of a system may not be visible beyond the interaction layer. Narrative context and audio-visual feedback are tools for designers to bridge the gap between players and the system thereby helping players make meaning from what they see. This gap is referred to as "the gulfs of execution and evaluation" by Norman [36], and it is bridged by aligning players' intentions, goals, and inputs with a permitted action sequence, perceivable outcome, and a consistent system status. Thus before an interaction method can be perceived as intuitive by a player, the way in which a player acts on the system needs to align with the game world.

HCI challenges need to be considered [54], especially for users with neurodegenerative diseases, where motor or/and cognitive impairments could impact speed and type of interactions. When there is delay at system's end, we see that as a usability problem. When delay happens at player's end, system needs to be gracefully waiting and in fact supporting at times (e.g., coyote time ${ }^{3}$ ). This may seem conflicting with the typical challenging nature of games; however, in a rehabilitation context the challenge should be packaged in the areas of higher player resources. Since our main concern is reducing frustration and increasing compassion in our design, the game response needs to be perceivable by the player such as through longer or lingering responses.

\subsection{Information layer}

The information layer bridges the information between structural core of the game and the presentation layer. A contextual metaphor (i.e. gardening) dictates the audio-visual qualities of the response (feedback from the system) and presentation of the game state [25]. Player personas from the previous stage are used to shape the context. Audio-visual elements include

3 Coyote time is a game design metaphor; jump still succeeds even if the player jumps a little bit too late. 
visual and sound effects, animation, user interface, and any kind of data presented to the player (health, mana, in-game resources, items, etc.). Understanding player's perspective is essential to identifying necessary elements required for the information layer. Questions such as: (1) What does the player see on screen when they are idle?", (2) "What does the player see after a certain action?", and (3) "How does the player know about their health/life/items/money?, (4) "How will the player know that they are (not) successful in their performance?", and (5) "How does the player know what they need to do in order to perform better?", provide insight to the players perspective. All answers should be within the contextual discourse of the metaphor and bring the developer to the scope of information layer. For us, this is a gardening metaphor. The questions should be as many as necessary until there is nothing to ask and nothing is left unclear about system's behavior. The necessity for encouraging feedback aligns with previous research $[14,15,17]$.

\section{Reflections and limitations}

We derived the design strategy presented in this paper while developing an exerbike-based game for PD rehabilitation. The game was refined during the development process, but has not been validated yet. We believe that adoption of our strategy will enable researchers to improve game-based interventions using a collaborative effort. Our intent is to tap into the hive mind for a critical evaluation, and to pursue a more collective effort to test and break the framework. We hope this work will provide a more diverse perspective to test/apply suggested methods, to find edge cases, and to contribute to improvement of self-directed and gamebased rehabilitation/training applications.

Due to multidisciplinary synthesis required for this paper, analysis of the literature and synthesis of the theory became intertwined. By using a "research through design" strategy, we believe development of a game-based rehabilitation for different patient groups is possible so long as game-based therapy is applicable in terms of accessibility. The stages of our design strategy facilitate a repeatable approach to develop specificapplication games rather than to develop one game that suits all rehabilitation needs. We feel that the strength of a product developed with this strategy depends on the rigor applied in the first stage. The ability of in-game tasks to represent the selected rehabilitation tasks require additional validation by a rehabilitation practitioner. In addition, the player-centric nature of the framework cannot be successful unless an iterative development process is employed including early playtests with the target demographic.
In this framework, we mention that player reservations may act as a barrier preventing participation. It is necessary to note that focusing solely on patient reservations in game design is not enough to overcome potential problems regarding them. For example, if there is a falls risk, a game element requiring displacement of the center of mass such as during a stepping task, the rehabilitation set-up still needs to consider precautions that protect the player from actually falling. Another consideration regarding games developed within this framework is game efficacy. It is important that the game can provide a suitable and adequate rehabilitation stimulus that produces reliable and measurable improvement in a player's healthrelated outcomes. With this paper, we present a strategy to design a product, yet we are not presenting a strategy to evaluate the effectiveness of that product. There could be cases where a game-based rehabilitation is effective for some patients while not for some others. This is a separate discussion that requires further study.

\section{Conclusion and future work}

In this paper, we presented a framework to facilitate the design process of games for rehabilitation. We hope that the framework guides other researchers through the complexity of combining rehabilitation and game design. We believe true contribution of games will emerge from their nature as systems that can absorb rehabilitation strategies into a self-directed (or game directed) therapy session that is motivational, engaging, adaptive, supervised, and trackable. In Parkinson's context, we want our system to merge aerobic exercise benefits with cognitive training for maximizing rehabilitation outcomes. Therefore, we combined cycling with an exercise based cognitive rehabilitation strategy based on [18] and [19], and developed game features that align with selected cognitive training tasks. In near future, we will test our prototype to refine and prepare for a longitudinal study to measure the effectiveness of our design. This will also help us reflect on the framework and refine our supporting questions. We welcome early adoption of the framework and collaboration in improving/developing it further.

\section{References}

[1] Dal Bello-Haas, V. (2002). A framework for rehabilitation of neurodegenerative diseases: planning care and maximizing quality of life. Journal of Neurologic Physical Therapy, 26(3), 115-129.

[2] Tece Bayrak, A., Wünsche, B., \& Lutteroth, C. (2016). Reviewing the Evidence: In Pursuit of a Framework for Parkinson Disease Rehabilitation with Games. Studies in Health Technology and Informatics, 231, 9-17. 
[3] Baranowski, T., Buday, R., Thompson, D. I., \& Baranowski, J. (2008). Playing for real: video games and stories for health-related behavior change. American journal of preventive medicine, 34(1), 74-82.

[4] Schoene, D., Valenzuela, T., Lord, S. R., \& de Bruin, E. D. (2014). The effect of interactive cognitive-motor training in reducing fall risk in older people: a systematic review. BMC geriatrics, 14, 107-107.

[5] Staiano, A. E., \& Flynn, R. (2014). Therapeutic uses of active videogames: a systematic review. Games for health journal, 3(6), 351-365.

[6] Parisod, H., Pakarinen, A., Kauhanen, L., Aromaa, M., Leppänen, V., Liukkonen, T. N., ... \& Salanterä, S. (2014). Promoting children's health with digital games: A review of reviews. GAMES FOR HEALTH: Research, Development, and Clinical Applications, 3(3), 145-156.

[7] Eichenberg, C., \& Schott, M. (2017). Serious games for psychotherapy: A systematic review. Games for health journal, 6(3), 127-135.

[8] de la Hera, T., Loos, E., Simons, M., \& Blom, J. (2017). Benefits and factors influencing the design of intergenerational digital games: a systematic literature review. Societies, 7(3), 18.

[9] Alves, M. L., Mesquita, B. S., Morais, W. S., Leal, J. C., Satler, C. E., dos Santos Mendes, F. A. (2018). Nintendo Wii ${ }^{\mathrm{TM}}$ Versus Xbox Kinect ${ }^{\mathrm{TM}}$ for Assisting People With Parkinson's Disease. Perceptual and motor skills, 125(3), 546565.

[10] Walton, C. C., Naismith, S. L., Lampit, A., Mowszowski, L., \& Lewis, S. J. (2017). Cognitive training in Parkinson's disease: a theoretical perspective. Neurorehabilitation and neural repair, 31(3), 207-216.

[11] Nuyens, F., Kuss, D. J., Lopez-Fernandez, O., \& Griffiths, M. D. (2017). The experimental analysis of problematic video gaming and cognitive skills: A systematic review. Journal de Thérapie Comportementale et Cognitive, 27(3), 110-117.

[12] Glizer, D., \& MacDonald, P. A. (2016). Cognitive training in Parkinson's disease: a review of studies from 2000 to 2014. Parkinson's Disease, 2016.

[13] Boot, W. R., Kramer, A. F., Simons, D. J., Fabiani, M., \& Gratton, G. (2008). The effects of video game playing on attention, memory, and executive control. Acta psychologica, 129(3), 387-398

[14] Assad, O., Hermann, R., Lilla, D., Mellies, B., Meyer, R., Shevach, L., Wieferich, J. (2011). Motion-based games for Parkinson's disease patients. In International Conference on Entertainment Computing (pp. 47-58). Springer.
[15] Pachoulakis, I., Papadopoulos, N., \& Spanaki, C. (2015). Parkinson's disease patient rehabilitation using gaming platforms: lessons learnt. arXiv preprint arXiv:1511.02589.

[16] Paraskevopoulos, I. T., Tsekleves, E., Craig, C., Whyatt, C., \& Cosmas, J. (2014). Design guidelines for developing customised serious games for Parkinson's Disease rehabilitation using bespoke game sensors. Entertainment Computing, 5(4), 413-424.

[17] Lohse, K., Shirzad, N., Verster, A., Hodges, N., Van der Loos, H. M. (2013). Video games and rehabilitation: using design principles to enhance engagement in physical therapy. Journal of Neurologic Physical Therapy, 37(4), 166175 .

[18] Duchesne, C., Lungu, O., Nadeau, A., Robillard, M. E., Boré, A., Bobeuf, F., ... \& Doyon, J. (2015). Enhancing both motor and cognitive functioning in Parkinson's disease: aerobic exercise as a rehabilitative intervention. Brain and cognition, 99, 68-77.

[19] Nadeau, A., Lungu, O., Duchesne, C., Robillard, M. È., Bore, A., Bobeuf, F., ... \& Doyon, J. (2017). A 12-week cycling training regimen improves gait and executive functions concomitantly in people with Parkinson's disease. Frontiers in human neuroscience, 10, 690.

[20] Uc, E. Y., Doerschug, K. C., Magnotta, V., Dawson, J. D., Thomsen, T. R., Kline, J. N., ... \& Bruss, J. (2014). Phase $\mathrm{I} / \mathrm{II}$ randomized trial of aerobic exercise in Parkinson disease in a community setting. Neurology, 83(5), 413-425.

[21] Bayrak, A. T. (2018). A Player-centric Game Design Paradigm with Compassion. CENTRIC 2018. Nice, France, pg: 58-63.

[22] Vuong, C. H., Ingalls, T., \& Abbas, J. J. (2011). Transforming clinical rehabilitation into interactive multimedia. In Proceedings of the 19th ACM international conference on Multimedia (pp. 937-940). ACM.

[23] Page, S. J., Gater, D. R., \& Bach-y-Rita, P. (2004). Reconsidering the motor recovery plateau in stroke rehabilitation. Archives of physical medicine and rehabilitation, 85(8), 1377-1381.

[24] Fullerton, T., Swain, C., \& Hoffman, S. (2004). Game design workshop: Designing, prototyping, \& playtesting games. CRC Press.

[25] Swink, S. (2008). Game feel: a game designer's guide to virtual sensation. CRC Press.

[26] Salen, K., \& Zimmerman, E. (2004). Rules of play: Game design fundamentals. MIT press.

[27] Adams, E. (2014). Fundamentals of game design. Pearson Education. 
[28] Schell, J. (2014). The Art of Game Design: A book of lenses. AK Peters/CRC Press.

[29] Hunicke, R., LeBlanc, M., \& Zubek, R. (2004). MDA: A formal approach to game design and game research. In Proceedings of the AAAI Workshop on Challenges in Game $A I$ (Vol. 4, No. 1, p. 1722).

[30] Neil, K. (2012, June). Game design tools: Time to evaluate. In Proceedings of the DiGRA Nordic Conference.

[31] Lazzaro, N. (2004). Why we play games: Four keys to more emotion in player experiences. In Proceedings of GDC.

[32] Ryan, R. M., Rigby, C. S., \& Przybylski, A. (2006). The motivational pull of video games: A self-determination theory approach. Motivation and emotion, 30(4), 344-360.

[33] Rigby, S., \& Ryan, R. (2007). The player experience of need satisfaction (PENS) model. Immersyve Inc, 1-22.

[34] Yee, N., Ducheneaut, N., Nelson, L., \& Likarish, P. (2011, May). Introverted elves \& conscientious gnomes: the expression of personality in world of warcraft. In Proceedings of the SIGCHI Conference on Human Factors in Computing Systems (pp. 753-762). ACM.

[35] Pruitt, J., \& Grudin, J. (2003, June). Personas: practice and theory. In Proceedings of the 2003 conference on Designing for user experiences (pp. 1-15). ACM.

[36] Norman, D. A. (1986). Cognitive engineering. User centered system design, 31, 61 .

[37] Norman, D. A. (1999). Affordance, conventions, and design. interactions, 6(3), 38-43.

[38] Foster, E. R., Spence, D., \& Toglia, J. (2018). Feasibility of a cognitive strategy training intervention for people with Parkinson's disease. Disability and rehabilitation, 40(10), 1127-1134.

[39] Phillips, L. H., Wynn, V. E., McPherson, S., \& Gilhooly, K. J. (2001). Mental planning and the Tower of London task. The Quarterly Journal of Experimental Psychology Section A, 54(2), 579-597.

[40] Csikszentmihalyi, M. (2013). Flow: The psychology of happiness. Random House.

[41] Horn, B., Cooper, S., \& Deterding, S. (2017). Adapting cognitive task analysis to elicit the skill chain of a game. In Proceedings of the Annual Symposium on ComputerHuman Interaction in Play (pp. 277-289). ACM.

[42] Bartle, R. (1996). Hearts, clubs, diamonds, spades: Players who suit MUDs. Journal of MUD research, 1(1), 19.

[43] Lindley, C. A., \& Sennersten, C. C. (2006). A cognitive framework for the analysis of game play: tasks, schemas and attention theory. In Workshop on the cognitive science of games and game play (Vol. 29).

[44] Clark, R. E., \& Estes, F. (1996). Cognitive task analysis for training. International Journal of Educational Research, 25(5), 403-417.

[45] Bayrak, A. T., Kumar, R., Tan, J., AhMu, D., Hohepa, J., Shaw, L. A., ... \& Wünsche, B. C. (2017). Balancing different fitness levels in competitive exergames based on heart rate and performance. In Proc. of the 29th Australian Conference on Computer-Human Interaction (pp. 210-217). ACM.

[46] Hamari, J., \& Tuunanen, J. (2014). Player types: A metasynthesis. Transactions of the Digital Games Research Association, vol. 1, no. 2, pp. 29-53.

[47] VandenBerghe, J. (2014). Engines of play. In Proc. of the first ACM SIGCHI annual symposium on Computer-human interaction in play-CHI PLAY (v. 14, pp. 476-476).

[48] VandenBerghe, J. (2016). Engines of Play: How Player Motivation Changes Over Time. In GDC Vault. [VIDEO]. Retrieved from: https://www.youtube.com/watch? $\mathrm{v}=\mathrm{Lg} 2 \mathrm{Gnd}$ Sat1E

[49] Belil, F. E., Alhani, F., Ebadi, A., \& Kazemnejad, A. (2018). Self-Efficacy of People with Chronic Conditions: A Qualitative Directed Content Analysis. Journal of clinical medicine, 7(11), 411. doi:10.3390/jcm7110411

[50] Zimmerman, J., Forlizzi, J., \& Evenson, S. (2007, April). Research through design as a method for interaction design research in HCI. In Proceedings of the SIGCHI conference on Human factors in computing systems (pp. 493-502). ACM.

[51] Thomas, J. R., Beatty, A. L., Beckie, T. M., Brewer L. C., Brown, T. M., Forman, D. E., Franklin, B. A., Keteyian, S. J., Kitzman, D. W., Regensteiner, J. G., Sanderson, B. K., Whooley, M.. A. (2019). Home-Based Cardiac Rehabilitation: A Scientific Statement from the American Association of Cardiovascular and Pulmonary Rehabilitation, the American Heart Association, and the American College of Cardiology. Circulation. 2019;140:e69-e89.

[52] Li, J., Erdt, M., Chen, L., Cao, Y., Lee, S. Q., Theng, Y. L. (2018). The Social Effects of Exergames on Older Adults: Systematic Review and Metric Analysis. J Med Internet Res, 20(6):e10486.

[53] Garcia-Agundez, A., Folkerts, A.-K., Konrad, R., Caserman, P., Tregel, T., Goosses, M., Göbel, S., Kalbe, E. (2019). Recent advances in rehabilitation for Parkinson's Disease with Exergames: A Systematic Review. Journal of NeuroEngineering and Rehabilitation, vol. 16, article 17.

[54] Shaw, L. A., Wünsche, B. C., Lutteroth, C., Marks, S. Callies, R. (2015). Challenges in virtual reality exergaming design. Proceedings of the 16th Australasian User Interface Conference (AUIC), vol. 162, 61-68. 